\title{
Examination of Stability of the Mathematical Predator-Prey Model by Observing the Distance between Predator and Prey
}

\author{
Priyasih, Miswanto, Alfiniyah
}

\begin{abstract}
Maintaining distance is one of the strategies that can be applied by prey to defend themselves or to avoid predatory attacks. This defense behavior can affect predation rates. The distance or difference in the number of prey and predator populations will affect the level of balanced ecosystem. The distance is also affecting predation rate, when there's a long distance between prey and predator thus the predation rate decreases and vice versa. The purpose of this thesis is to analyze the stability of the mathematical equilibrium on predator-prey model by observing the distance. There are two types of model being observed, type one uses exponential growth model and type two is using a logistic growth model. The analytics results obtain three equilibrium points, namely the unstable extinction equilibrium point, and the asymptotically stable predator extinction with certain conditions and asymptotically stable coexistence with certain conditions. Then numerical simulation is conducted to support the analytical results.
\end{abstract}

Index Terms: Predator-Prey model, distance, equilibrium point, stability.

\section{INTRODUCTION}

Species are groups of individual which show predominate characteristics that differ from other groups either morphologically, physiologically, or biochemically. The large number of species present on earth affect in diversity of species. Species diversity is a variation of the diversity of species that live in particular locations ${ }^{9}$.

Species diversity diversifies biological community or a group of species that occupy a particular environment and interact with each other. All organisms that live in a community and all abiotic factors that interact with these organisms are called ecosystems ${ }^{6}$.

In an ecosystem, species have different roles according to their needs of food. One example is animal species have their own preferred needs of food. As a result of these needs of food, the interaction of prey-prey increases. The specific relationship between preys is called the food chain ${ }^{9}$.

Predation is the interaction between organisms where one organism preys on another organism. The organism that

\footnotetext{
Revised Manuscript Received on September 22, 2019.

Priyasih, Department of Mathematics, Faculty of Science and Techonolgy, Universitas Airlangga, Surabaya, Indonesia

Miswanto, Departemen of Mathematics Faculty of Science and Technology, Airlangga University, Surabaya, Indonesian.

Alfiniyah, Department of Mathematics, Faculty of Science and

Techonolgy, Universitas Airlangga, Surabaya, Indonesia
}

preys is called predator, while the organism that is preyed is called prey. The relationship between predators and preys affect the abundance of organisms in an ecosystem ${ }^{18}$.

Interactions between two species can be presented mathematically using mathematical models. In 1926 Vito Volterra developed a model from Alfred J. Lotka which described the relationship of prey-prey to fish species into the mathematical Lotka-Volterra model. Each population is predator and prey influenced by the number of births, deaths, and interactions between the two ${ }^{5}$. The interaction between predators on preys is done quickly when there are no restrictions from the environment. In 1959, Holling lowered the model which limits the rate of predators preying prey or predation rates from predators.

Studies of predator-prey model have developed over the past few years. Jana et al (2015) examine the model to differentiate preys into two classes, strong prey and weak prey [10]. Ashine and Gebru (2017) examined the mathematical predator-prey model by adding Holling II's functional response and comparing the constant proportion of protected prey and unprotected prey [3].

In this paper, the mathematical model of predator-prey written by Liu and Huang (2018) will be reviewed by changing the functional response of Holling $I V$ to a distance response between predators and prey, and eliminating harvesting factors [12]. With the condition of short distance between predators and prey, there is an increase in the prey process. But when there is a long distance between the two, prey process will decrease.

\section{Equilibrium Points and ANAlysis of Equilibrium Points' STABILITY}

\section{A. Equilibrium Points and Analysis of Equilibrium Points' Stability}

In this section we examine the stability of the equilibrium points of two mathematical models of predator-prey by observing the distance between predators and preys. The difference between the two model is in the population growth of preys. The first model is when preys use the exponential growth model, and the second is when preys use the logistic growth model. From both models the equilibrium points will be determined and the equilibrium point's stability test.

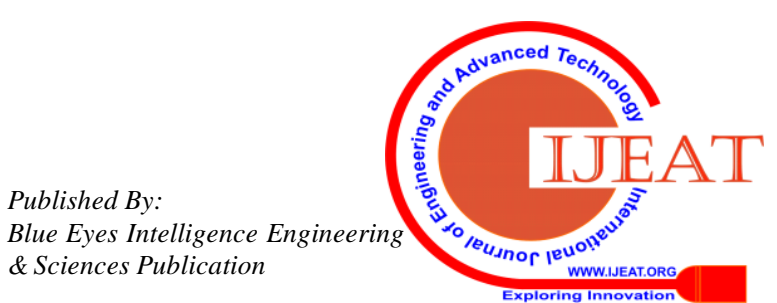


B. The Mathematical Model of Predator-Prey by Observing the Distance between Predators and Prey Using the Exponential Growth Model

In this sub-section, a mathematical model of predator-prey is analyzed by observing the distance between predators and prey which refers to a paper written by Liu and Huang (2018) [12]. The model used consists of two compartments, population of prey species $x(t)$ and population of predator species $y(t)$.

The assumptions used in the mathematical model of predator-prey by considering the distance between predators and prey when using the exponential growth model are as follows:

1. The growth model of the two species is using the exponential growth model.

2. Prey's natural death rate is disregarded.

3. Interaction of predator and prey by observing the distance.

In tables I and II are given definitions of variables and parameters used in mathematical models of predator-prey by observing the distance between predators and prey.

Table- I: Notation and Description of First Variable Model

$\begin{array}{cc}\text { Variable } & \text { Description } \\ x(t) & \begin{array}{c}\text { Number of species population of prey at the } \\ \text { time } t\end{array} \\ y(t) & \begin{array}{c}\text { Number of species population of predator at } \\ \text { the time } t\end{array} \\ \end{array}$

Table- II: Notation and Description of First Parameter Model

\begin{tabular}{cc}
\hline Parameter & Description \\
\hline$a$ & $\begin{array}{c}\text { The rate of growth of prey species } \\
\text { The rate of prey species predation when } \\
\text { preyed on predators }\end{array}$ \\
$c$ & The natural mortality rate of predator \\
species
\end{tabular}

The following is formulated model :

$$
\begin{aligned}
& \frac{d x}{d t}=a x-\frac{b x y}{1+(x-y)^{2}} \\
& \frac{d y}{d t}=-c y+\frac{d x y}{1+(x-y)^{2}} .
\end{aligned}
$$

where, $x_{x} y \geq 0$ and $a_{v} b_{v} c_{x} d>0$.

Equation (1) describes the rate of change in prey species population per unit time. The prey species population will increase because the population growth rate of the prey species is as exponentially large as $a x$. Furthermore the prey species population will decrease when there is competition with predator population by $\frac{b x y}{1+(x-y)^{2}}$.

Equation (2) describes the rate of change in predator species population per unit time. The predator species population will increase when there is competition with prey population by $\frac{d x y}{1+(x-y)^{2}}$. Furthermore, the predator species population will be reduced due to natural death of predators large as $c y$.

\subsubsection{Equilibrium Points model}

The model above has two equilibrium points, namely the extinction equilibrium point $\varepsilon_{0_{1}}=(0,0)$ and the coexistence equilibrium point $\varepsilon_{1_{1}}=\left(x_{x} \frac{a d}{b c} x\right)$.

\subsubsection{Analysis of Local Stability Model}

In this section an analysis of local stability of each equilibrium point is done. This analysis aims to determine the dynamics of system behavior on the model.

The following is an analysis of local stability from the equilibrium points $\varepsilon_{0_{1}}$ and $\varepsilon_{1_{1}}$.

\section{a. Local Stability of Extinction Equilibrium Point $\left(\varepsilon_{0_{1}}\right)$}

The first step taken is to substitute the extinction equilibrium point $\varepsilon_{0_{1}}(x, y)=(0,0)$ into the jacobian matrix, thus obtained by

$l\left(\varepsilon_{0_{1}}\right)=\left[\begin{array}{cc}a & 0 \\ 0 & -c\end{array}\right]$

Furthermore, Jacobian matrix $7\left(\varepsilon_{0_{1}}\right)$ is formed into a characteristic equation through $\left|\lambda I-J\left(\varepsilon_{0_{1}}\right)\right|=0$ as follows:

$$
(a-a)(a+c)=0
$$

From the characteristic equation (.3) an eigen value is obtained $\lambda_{1}=a$ and $\lambda_{2}=-c$.

The equilibrium points above will asimtotic stable if and only all of eigen value from the characteristic equation (3) have negative value. Because there is an eigen value $\lambda_{1}=a>0$, the extinction equilibrium point $\left(\varepsilon_{0_{1}}\right)$ is unstable.

\section{b. Local Stability Coexistence Equilibrium Point $\left(\varepsilon_{1_{1}}\right)$}

The first step taken is to substitute the extinction equilibrium point

$\varepsilon_{1_{1}}(x, y)=\left(x, \frac{a d}{b e} x\right)$ into the jacobian matrix, thus obtained by

(1) $l\left(\varepsilon_{1_{1}}\right)=\left[\begin{array}{cc}\left(\frac{a q+\varepsilon_{1} b y}{q}\right) & \left(-\frac{b x \varepsilon_{2}}{q}\right) \\ \left(-\frac{d y \varepsilon_{1}}{q}\right) & \left(\frac{-c q+d x \varepsilon_{2}}{q}\right)\end{array}\right]$

(2) where

$$
\begin{aligned}
& y=\frac{a d}{b c} x \\
& q=\left(1+x^{2}+y^{2}-2 x y\right)^{2} \\
& e_{1}=x^{2}-1-y^{2} \\
& e_{2}=x^{2}+1-y^{2}
\end{aligned}
$$

Furthermore, Jacobian matrix $l\left(\varepsilon_{1_{1}}\right)$ is formed into a characteristic equation through $\left|\lambda I-J\left(\varepsilon_{1_{1}}\right)\right|=0$ as follows:

$\lambda^{2}+c_{1} \lambda+c_{2}=0$

where,

$c_{1}=\frac{1}{q}\left(-a q-e_{1} b y+c q-d x e_{2}\right)$ 
$c_{2}=\frac{1}{q}\left(-a c q+e_{2}(a d x-b c y)\right)$

The equilibrium points above will asimtotic stable if and only all of eigen value from the characteristic equation (4) have negative value. The extinction equilibrium point $\left(\varepsilon_{1_{1}}\right)$ is asimtotic stable with the existence conditions:

i. $\quad \frac{c^{2} q}{\operatorname{acq}+a d \theta_{1} x+c d \theta_{2} x}>1$

C. The Mathematical Model of Predator-Prey by Observing the Distance between Predators and Prey Using the Logistic Growth Model

The assumptions used in the mathematical model of predator-prey by considering the distance between predators and prey when using the logistic growth model are as follows:

1. The growth model of prey species is using the logistic growth model.

2. Interaction of predator and prey by observing the distance.

In tables III and IV are given definitions of variables and parameters used in mathematical models of predator-prey by observing the distance between predators and prey.

Table- III: Notation and Description of Second Variable Model

\begin{tabular}{cc}
\hline Variable & Description \\
\hline$x(t)$ & $\begin{array}{c}\text { Number of species population of prey at the } \\
\text { time } t\end{array}$ \\
$y(t)$ & $\begin{array}{c}\text { Number of species population of predator at } \\
\text { the time } t\end{array}$ \\
\hline
\end{tabular}

Table- IV: Notation and Description of Second Parameter Model

\begin{tabular}{cc}
\hline $\begin{array}{c}\text { Paramete } \\
\mathbf{r}\end{array}$ & Description \\
$r$ & The rate of intrinsic growth \\
$K$ & Carrying capacity from habitats \\
$b$ & The rate of prey species predation when preyed \\
& on predators \\
$c$ & The natural mortality rate of predator species \\
$d$ & The rate of predatory species predation in \\
& preying on preys
\end{tabular}

The following is formulated model:

$$
\begin{aligned}
& \frac{d x}{d t}=r x\left(1-\frac{x}{K}\right)-\frac{b x y}{1+(x-y)^{2}} \\
& \frac{d y}{d t}=-c y+\frac{d x y}{1+(x-y)^{2}}
\end{aligned}
$$$$
\text { where, } x_{x} y \geq 0 \text { and } r_{x} K_{x} b_{v} c_{v} d>0
$$

Equation (5) describes the rate of change in prey species population per unit time. The prey species population will increase because the population growth rate of the prey species is as logistically large as $r x\left(1-\frac{x}{K}\right)$. Furthermore the prey species population will decrease when there is competition with predator population by $\frac{b x y}{1+(x-y)^{2}}$.
Equation (6) describes the rate of change in predator species population per unit time. The predator species population will increase when there is competition with prey population by $\frac{d x y}{1+(x-y)^{2}}$. Furthermore, the predator species population will be reduced due to natural death of predators large as $c y$.

\subsubsection{Equilibrium Points model}

The model above has three equilibrium points, namely the extinction equilibrium point $\varepsilon_{0_{2}}=(0,0)$, the extinction of predators species $\varepsilon_{1_{2}}=\left(K_{v}, 0\right)$ and the coexistence equilibrium point $\varepsilon_{2_{2}}$ hasn't obtained with analitycal then will be analyze with numerical simulation.

\subsubsection{Analysis of Local Stability Model}

In this section an analysis of local stability of each equilibrium point is done. This analysis aims to determine the dynamics of system behavior on the model.

The following is an analysis of local stability from the equilibrium points $\varepsilon_{0_{2},{ }^{,}} \varepsilon_{1_{2}}$ and $\varepsilon_{2_{2}}$.

\section{a. Local Stability of Extinction Equilibrium Point $\left(\varepsilon_{0_{2}}\right)$}

The first step taken is to substitute the extinction equilibrium point $\varepsilon_{0_{2}}(x, y)=(0,0)$ into the jacobian matrix, thus obtained by

$l\left(\varepsilon_{0_{2}}\right)=\left[\begin{array}{cc}r & 0 \\ 0 & -c\end{array}\right]$

Furthermore, Jacobian matrix $7\left(\varepsilon_{\mathrm{O}_{2}}\right)$ is formed into a characteristic equation through $\left|\lambda I-J\left(\varepsilon_{0_{2}}\right)\right|=0$ as follows:

$$
(\lambda-r)(\lambda+c)=0
$$

From the characteristic equation (7) an eigen value is obtained

$\lambda_{1}=r$ and $\lambda_{2}=-c$

The equilibrium points above will asimtotic stable if and only all of eigen value from the characteristic equation (7) have negative value. Because there is an eigen value $\lambda_{1}=r>0$, the extinction equilibrium point $\left(\varepsilon_{0_{1}}\right)$ is unstable.

b. Local Stability of Extinction of Predators species $\left(\varepsilon_{1_{z}}\right)$

The first step taken is to substitute the extinction equilibrium point $\varepsilon_{0_{2}}(x, y)=(0,0)$ into the jacobian matrix, thus obtained by

$$
l\left(\varepsilon_{1_{2}}\right)=\left[\begin{array}{cc}
-r & p_{1} \\
0 & p_{2}
\end{array}\right]
$$

(5) where,

(6) $p_{1}=\frac{-\left(b K-b K^{a}\right)}{K^{4}+2 K^{2}+1}$

$p_{2}=\frac{\left(d K+d K^{2}\right)}{K^{4}+2 K^{2}+1}-c$

Furthermore, Jacobian matrix $l\left(\varepsilon_{1_{2}}\right)$ is formed into a characteristic equation through $\left|\lambda I-J\left(\varepsilon_{1_{2}}\right)\right|=0$ as follows:

$$
(\lambda+r)\left(\lambda-p_{2}\right)=0
$$


From the characteristic equation (8) an eigen value is obtained $\lambda_{1}=-r$ and $\lambda_{2}=p_{2}$

The extinction equilibrium point of predators species $\left(\varepsilon_{1_{2}}\right)$ is asymptotic stable if $\frac{d K+d K^{3}}{c K^{4}+2 c K^{2}+c}<1$.

\section{c. Local Stability Coexistence Equilibrium Point $\left(\varepsilon_{2_{z}}\right)$}

Based on the description of the equilibrium points that have been obtained, to determine the stability of the equilibrium in terms of coexistence $\left(\varepsilon_{2_{z}}\right)$ analytically in eigen values are difficult to determine. So to find out the stability, numerical methods are used by using software Matlab. This simulation is done by giving parameter values and three initial values for $x(0)$ and $y(0)$. The initial values and parameter values used are illustrated in tables V and VI. This simulation is carried out at time $t=0$ to $t=100$.

Table- V: Initial value

\begin{tabular}{cccc}
\hline Initial Value & $\boldsymbol{x}(\mathbf{0})$ & $\boldsymbol{y}(\mathbf{0})$ & Color \\
\hline 1 & 145 & 65 & Red \\
2 & 85 & 55 & Blue \\
3 & 120 & 15 & Green
\end{tabular}

\begin{tabular}{cc} 
Table- VI: Parameter value \\
\hline Parameter & Value \\
\hline$r$ & 2 \\
$K$ & 120 \\
$b$ & 1 \\
$d$ & 4 \\
$c$ & 0.01 \\
\hline
\end{tabular}

All parameter value based on paper written by Liu and Huang (2018) [12].

The following are the results of numerical simulations of the point phase fields equal to coexistence:

Fig. 1 is a graph of the phases of the prey species population and predator species in the mathematical model of predator-prey by observing the distance between predators and prey with the existence conditions $\left(\varepsilon_{2_{z}}\right)$. Based on Fig. 1 with the three initial values used, it shows that all the graphs tend to go to the equilibrium point of the coexistence of species prey and predator is $(119,334)$, in other words the graph is convergent. Thus the model tends to be asymptotic stable at the equilibrium point of coexistence.

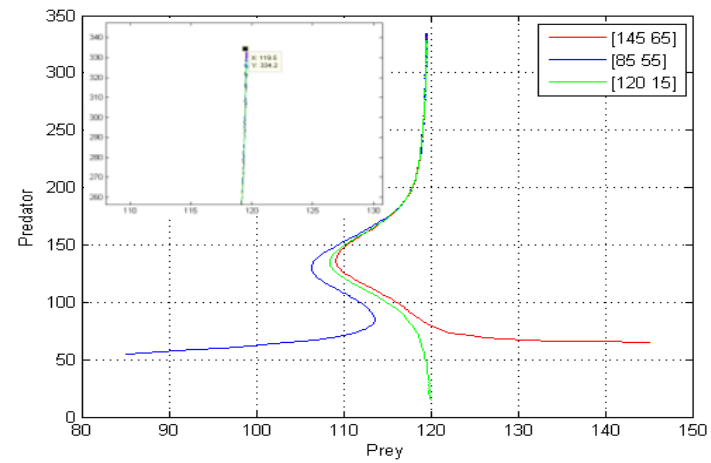

Fig. 1. Phase graphs of fields $x_{x} y$ in mathematical model of predator-prey by observing the distance between predators and prey when using logistic growth model with different initial values.
D. Numerical Simulation of Comparison and Interpretation of Mathematical Model of Predator-Prey by Observing the Distance between Predators and Prey by Using Exponential and Logistics Growth Model

In this paper, a comparison of mathematical model of predator-prey is simulated by observing the distance between predators and prey by using exponential and logistic growth model. This is done to determine the difference in the number of subpopulations in the first and second model. Furthermore, the results obtained from the two subpopulations are directly compared. Simulation is done in $\mathrm{t}=1$, with the initial value $\left(x_{1}(0), x_{2}(0)\right)=(100,65)$. The following is the result of numerical simulation of mathematical model of predator-prey by observing the distance between predators and prey when using the exponential growth model.

Fig. 2 illustrates the graph between prey species and predatory species during $t=1$. At the beginning of the observation based on Fig. 2 it can be seen that the prey species experienced an increase due to an exponentially rising birth which caused the predator species to decline exponentially because death. Then the prey species continued to increase so that the predator species also experienced a continuous decline nearing extinction. This happens because the distance or difference between the two populations is getting bigger. At the end of the observation it was found that the population of each species, prey species as many as 265 species and predator species as many as 25 species.

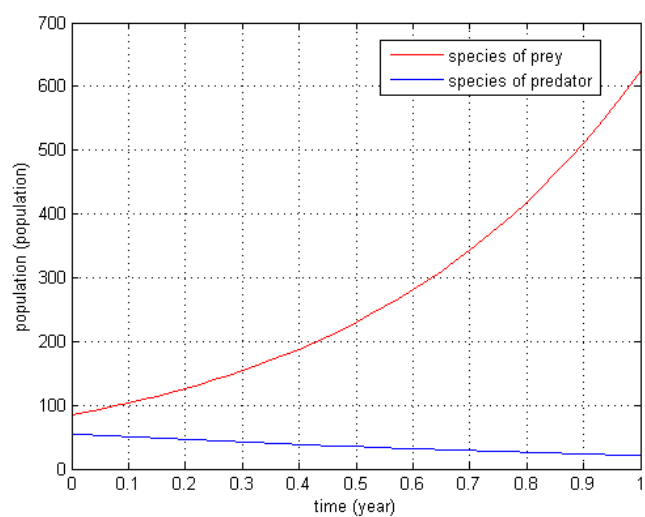

Fig. 2. Prey population dynamics $(x(t))$ and predator population $(y(t))$ on mathematical model of predator-prey by observing the distance between predators and prey when using the exponential growth model.

Next is a numerical simulation of mathematical model of predator-prey by observing the distance between predators and prey when using the logistic growth model.

Fig. 3 illustrates the graph between prey species and predator species during $\mathrm{t}=1$. At the beginning of the observation based on Fig. 4 it can be seen that the prey species has increased due to logistical growth. While the predator species has decreased due to the natural death. Then the prey species tend to increase constantly towards supporting capacity from nature to the end of the

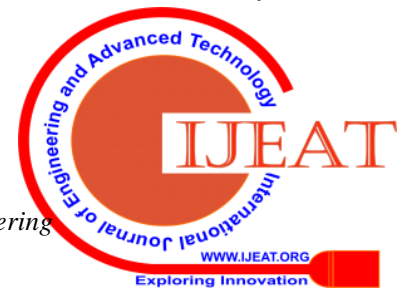


observation. While predator species tend to decrease constantly nearing extinction until the end of the observation. As a result at the end of the observation, the population of prey species is 116 species while predator species is 27 species.

Furthermore, to facilitate the writing, by taking mathematical model of predator-prey into account the distance between predators to prey when using an exponential growth model as the first model and by taking the mathematical model of predator-prey into account the distance between predator to prey when using logistic growth model as the second model. The following is a simulation of the comparison between prey species and predator species from the two models.

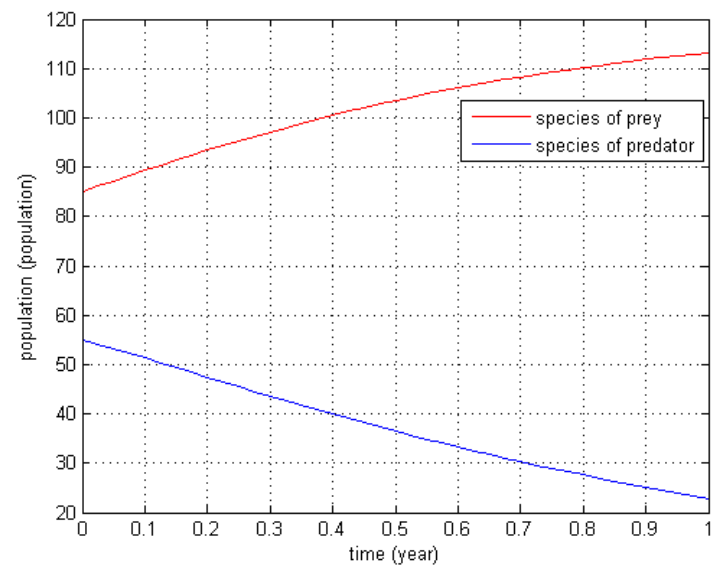

Fig. 3. Prey Population dynamics $(x(t))$ and predator population $(y(t))$ on mathematical model of predator-prey by observing the distance between predators and prey when using the logistic growth model.

Fig. 4 shows a comparison between prey species population $(x(t))$ from the first and second model. It appears that there are differences from the first and second model. At the beginning of the observation the prey species from the first model experienced a more significant increase compared to the second model. The increase occurs continuously until the end of the observation which shows the number of prey populations from the first model overtakes the prey population of the second model. Thus it can be concluded that using the first model, a balanced ecosystem is difficult to achieve because there are no limitations from nature.

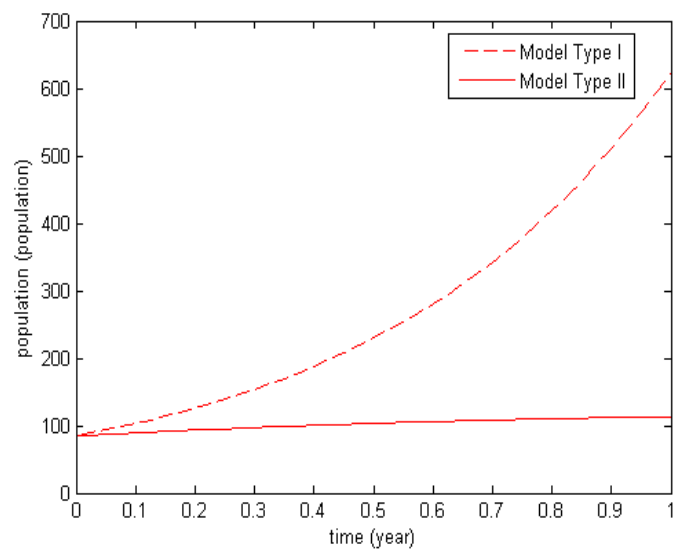

Fig. 4. Comparison between prey species population $(x(t))$
Comparison of population numbers of Prey species $(x(t))$ in both models is presented in Table VII.

Table- VII: Comparison of population numbers of Prey species $(x(t))$ in $t=1$

Conditions

Population Number of Prey Species

First Model $(x(t))$

Second Model

Next, a comparison of the Predator species $(y(t))$ in both models is presented in Fig. 5.

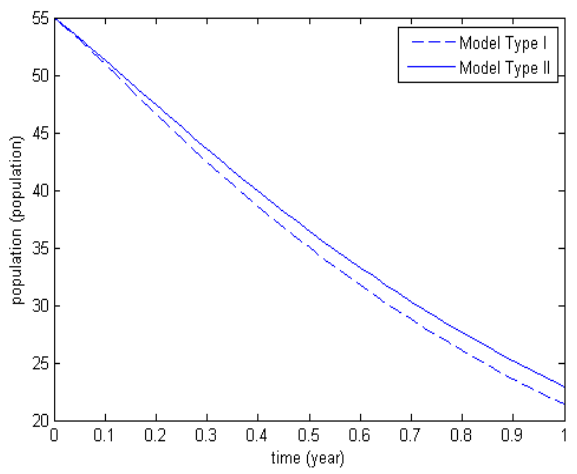

Fig. 5. Comparison of Predator Species Population Dynamics $(y(t))$

Fig. 5 shows a comparison of the predator species population $(y(t))$ from the first and second model. It appears that the two models are similar. At the beginning of the observation the predator species from both models experienced a significant decline. Then the two predator species move towards extinction at a point until the end of the observation. It is found that the predator population at the end of the observation of the second model overtakes the predator population of the latter. Thus it can be concluded that by using the second model, the predator extinction runs slower so that the ecosystem balance will be achieved.

Comparison of the predator species population $(y(t))$ in both models is presented in Table VIII.

Table- VIII: Comparison of the predator species population $(y(t))$ in $t=1$.

\begin{tabular}{cc}
\hline Conditions & $\begin{array}{c}\text { Population Number of Predator } \\
\text { Species }(\boldsymbol{y}(\boldsymbol{t}))\end{array}$ \\
\hline First Model & 25 \\
Second Model & 27 \\
\hline
\end{tabular}

\section{Conclusion}

Based on the discussion described in the previous chapter, conclusions can be drawn as follows:

1. Mathematical model of predator-prey by observing the distance between predators and prey when using the exponential growth model has two equilibrium points, namely:

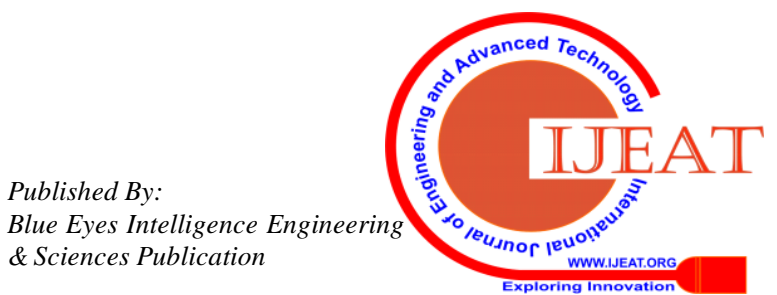


a. Extinction equilibrium point $\varepsilon_{0_{1}}(x, y)=(0,0)$ which is unstable.

b. Coexistence equilibrium point $\varepsilon_{1_{1}}(x, y)=\left(x, \frac{a d}{b c} x\right)$ which tends to be asymptotic stable with condition $\frac{c q}{a q+e_{1} b y+d x \theta_{2}}>1$ and $\frac{a b c d e_{2} x}{a b c^{2} q+a b c d \theta_{2} x}>1$

2. The mathematical model of predator-prey by considering the distance between predators and prey when using the logistic growth model has three equilibrium points, namely:

a. The extinction equilibrium point $\varepsilon_{0_{2}}(x, y)=(0,0)$, which is unstable.

b. The extinction of predator species equilibrium point $\varepsilon_{1_{2}}(x, y)=(K, 0)$ which is asymptotically stable if it meets $\frac{d K+d K^{3}}{c K^{4}+2 c K^{2}+c}<1$.

c. Coexistence equilibrium point $\varepsilon_{2_{2}}$ which tends to be asymptotic stable at coexistence equilibrium point $\varepsilon_{2_{2}}(x, y)=(119,334)$.

3. In comparison of numerical simulations mathematical model of predator-prey by observing the distance between predators and prey, has concluded that exponential growth model increases prey species more significantly compared to the logistic growth model. Also, the extinction in predator species happens faster using the exponential growth model.

\section{REFERENCES}

1. R. Altwegg, "Functional Response and Prey Defence Level in an Experimental Predator-Prey System," Evolutionary Ecology Research, vol. 8, 2006, pp. 115-128.

2. H. Anton, Aljabar Linier Elementer, Erlangga, Jakarta, 2005.

3. A. B. Ashine, and dan Gebru, "Mathematical Modeling of a Predator-Prey Model with Modified Leslie-Gower and Holling-Type II Schemes," Mathematical and Decision Sciences, vol. 17, 2017, pp. 2249-4626

4. N. Bacaer, A Short History of Mathematical Population Dynamics Ninth Edition, Springer London Dordrecht Heidelberg, New York, 2011.

5. F. Brauer, and C. dan Castillo-Chaves, Mathematical Models in Population Biology and Epidemiology, Second Edition, Springer, New York, 2010

6. N. A. Campbell, J. B. Reece, L. G. dan Mitchell, Biologi Edisi Kelima Jilid

https://books.google.co.id/books?id=x9OOphMNmxwC\&pg=RA1-PA40 \&dq=campbell+edisi+5+jilid+3\&hl=id\&sa=X\&ved=0ahUKEwi10umhl pffAhVDeH0KHYyYBLIQ6AEIKDAA\#v=onepage $\& \mathrm{q}=$ ekosistem $\& \mathrm{f}=\mathrm{f}$ alse, 1 November 2018.

7. J. Hofbauer, and K. dan Sigmund, Evolutionary Games and Population Dynamics, First Edition, Cambridge University Press, New York, 1998.

8. M. E. Hunsicker, L. Cianelli, and K. M. Bailey, "Functional Responses and Scaling Predator-Prey Interactions of Marine Fishes : Contemporary Issues and Emerging Concepts," Ecology Letters, vol. 14, 2011, pp. 1288-1299

9. M. Indrawan, R. B. Primack, and J. dan Supriatna, Biologi Konservasi Edisi Revisi, Yayasan Pusaka Obor, Indonesia, 2012.

10. S. Jana, A. Gurai, S. Guria, and T. K. dan Kar, "Global Dynamics of a Predator, Weaker Prey and Stronger Prey System," Applied Mathematics and Computation, vol. 250, 2015, pp. 235- 248

11. W. G. Kelley, and A. C. dan Peterson, The Theory of Differential Equation : Classical and Qualitative, Springer Science and Business Media, New York, 2010

12. X. Liu, and Q. dan Huang, "The Dynamics of a Harvested Predator-Prey System with Holling Type IV Functional Response," Biosystems, vol 169-170, 2018, pp. 26-39.

13. J. D. Logan, A First Course of Differential Equations, University of Nebraska at Lincoln, USA, 2011.

14. D. R. Merkin, Introduction to the Theory of Stability, Springer, New York, 1997.
15. J. N. Ndam, and T. G. dan Kassem, "A Mathematical Model for The Dynamics of Predator-Prey Interactions in A Three-Throphic Level Food Web," Continental J. Applied Sciences, vol. 4, 2009, pp. 32-43.

16. G. J. Olsder, Mathematical System Theory, Delft, The Natherland, 2003.

17. L. Perko, Differential Equations and Dynamical Systems, Third Edition. Springer-Verlag, New York, 2001.

18. H. Purnomo, Pengantar Pengendalian Hayati, Edisi I, Penerbit Andi, Yogyakarta, 2010.

19. G. T. Skalski, and J. E. dan Gilliam, "Functional Responses with Predator Interferences Variable Alternative to The Holling Type II Model," Ecology, vol. 82, 2001, pp. 3083-3092.

20. C. H. Tsai, and H. C. dan Pao, "Global Stability for The Lesllie-Gower Predator-Prey System with Time Delayed and Holling Type Functional Response," Tunghai Science, vol. 6, 2004, pp. 43-72.

21. D. G. Zill, and M. R. dan Cullen, Differential Equations with Boundary-Value Problems, Nelson Education, Ltd., Canada, 2009.

\section{AUTHORS PROFILE}

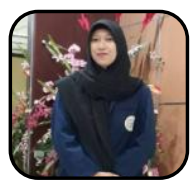

Martin Priyasih Bachelor of Department of Mathematics, Faculty of Science and Techonolgy, Universitas Airlangga, Surabaya, Indonesia

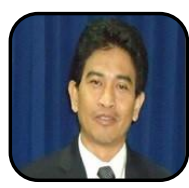

Miswanto, Associate Professor Department of Mathematics, Faculty of Science and Techonolgy, Universitas Airlangga, Surabaya, Indonesia

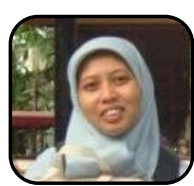

Cicik Alfiniyah, Ph.D., Lecturer Department of Mathematics, Faculty of Science and Techonolgy, Universitas Airlangga, Surabaya, Indonesia 